\title{
Proceeding
}

Supplementary Issue: Spring Conferences of Sports Science. Costa Blanca Sports Science Events, 19-20 June 2020. Alicante, Spain.

\section{From "sliding" to "winding" filaments theory: A narrative review of mechanisms behind skeletal muscle contraction}

\author{
PIETRO MONTESANO ${ }^{1}$, STEFANO PALERMI², BRUNO MASSA², FILOMENA MAZZEO1 \\ ${ }^{1}$ Department of Sport Sciences and Wellness, University of Naples Parthenope, Naples, Italy \\ 2Department Public Health, University of Naples "Federico II", Naples, Italy
}

\begin{abstract}
The physiological mechanisms behind muscle contraction are a main concept in sport medicine and rehabilitation. The sarcomere is the functional unit of skeletal muscle and several proteins definite its complex structure. The most common theory to explain muscle contraction was proposed in the last 50's and has become widely popular and accepted: the "sliding filaments" theory. Even if this hypothesis was able to justify some form of muscle contraction, other processes are not fully described by it. Eccentric contraction and some phenomena, like the "force enhancement during stretch" concept described in the 2002, are not explicable according to the sliding filament theory. Therefore, several hypotheses have been suggested over the years, such as the "popping sarcomeres" theory and the "winding filament" theory. Some other proteins, like titin, have gained a main role in the physiology of the sarcomere and should be relevant to explain mechanisms of eccentric contraction, where the sarcomere generates highest level of tension while it is lengthening. The aim of this review is to summarize the physiological theories of muscle contraction and to define concepts applicable in sport medicine and in rehabilitation areas.
\end{abstract}

Keywords: Muscle contraction; Actin; Myosin; Titin.

\section{Cite this article as:}

Montesano, P., Palermi, S., Massa, B., \& Mazzeo, F. (2020). From "sliding" to "winding" filaments theory:

A narrative review of mechanisms behind skeletal muscle contraction. Journal of Human Sport and

Exercise, 15(3proc), S806-S814. doi:https://doi.org/10.14198/ihse.2020.15.Proc3.31

Corresponding author. Department of Sport Sciences and Wellness, University of Naples Parthenope, Naples, Italy.

E-mail: pieromontesano@libero.it

Supplementary Issue: Spring Conferences of Sports Science. Costa Blanca Sports Science Events, 19-20 June 2020. Alicante, Spain.

JOURNAL OF HUMAN SPORT \& EXERCISE ISSN 1988-5202

(c) Faculty of Education. University of Alicante

doi:10.14198/jhse.2020.15.Proc3.31 


\section{INTRODUCTION}

There are two modality of muscle contraction (Padulo, Laffaye, Chamari, \& Concu, 2013) (Sweeney \& Hammers, 2018): dynamic (isotonic, isokinetic, auxotonic and plyometric) and static (isometric). Isotonic contraction occurs when a muscle changes its length by moving a load that remains constant for the whole duration of the shortening phase: it can be divided into concentric (positive phase - the muscle shortens developing tension) and eccentric (negative phase - the muscle stretches developing tension) contractions. Isokinetic contraction occurs when the muscle develops the maximum effort for the entire amplitude of the movement, contracting at a constant speed. Auxotonic contraction progressively increases with muscle shortening. Plyometric contraction is an explosive concentric contraction, immediately preceded by an eccentric contraction. Isometric contraction occurs when the muscle contracts without changing its length and without therefore shifting the load.

These differences have impact on several functions of skeletal muscles, determining different level of tension. Recent evidences (Naugle, Naugle, Fillingim, \& Riley, 2014) showed that isometric contraction could modulate pain perception (Rio et al., 2015), while eccentric contractions could have a role in the rehabilitation of muscle injuries and tendinopathies (Loiacono et al., 2019). Isometric contractions are useful to contrast hypotrophy. Plyometric exercises could be adopted both to increase sport performance and as training method (Davies, Riemann, \& Manske, 2015) (Montesano et al., 2020).

Physiological mechanisms behind these different types of contractions are not fully understood. Over the years several theories have been proposed to define the function of the sarcomere, the functional unit of skeletal muscle. While mechanism behind isometric and isotonic concentric contraction are widely accepted, several doubts persist about mechanisms of eccentric contraction and about the rule of non-contractile structures (i.e. connective tissue) during plyometric contraction.

Knowing these mechanisms could be relevant to define the effect of physical activity (Jones \& Rutherford, 1987) (Mazzeo, Tafuri, \& Montesano, 2020), rehabilitation process and physical agents on muscle tissue in normal and pathological conditions (B Corrado, Albano, et al., 2019) (Vola et al., 2018).

Moreover, skeletal muscle contraction is managed by neural efferences, modulated by proprioceptive afferences from muscular and non-muscular tissues. Indeed, beyond muscle architecture, muscle contraction could be influenced by proprioceptive stimuli rising from articular structure, and this process is called arthogenic muscular inhibition (AMI) (Rice, McNair, Lewis, \& Dalbeth, 2014). Therefore, some physical agents acting on non-muscular structure, such as cryotherapy, electrical stimulation or electromagnetic field, could have functional impact on muscle tissue (Sonnery-Cottet et al., 2019) (Servodio lammarrone et al., 2016).

The present review aims to summarize the physiological hypothesis of muscle contraction and to define concepts applicable in sport medicine and in rehabilitation areas.

\section{THE SARCOMERE: FUNCTIONAL UNIT IN SKELETAL MUSCLE}

Skeletal muscle is a complex and organized tissue made by bundles of muscle fibre (Exeter \& Connell, 2010). Each of these (myofibers) contains several myofibrils: these represent muscle cells, composed by sarcomeres. Bundles of myofibers form the fascicles, and bundles of fascicles form the muscle tissue. Each one of these layers are covered by the extracellular matrix (Lieber, 2009) and are supported by the 
cytoskeletal network. Connective tissue of muscle is a complex entity, made by extra-cellular matrix (ECM) and an extensive network of capillaries and nerves (Grzelkowska-Kowalczyk, 2016) (Humphrey, Dufresne, \& Schwartz, 2014). Traditionally, ECM in skeletal muscle is organized into three structures: epimysium, perimysium, and the endomysium (Gillies \& Lieber, 2011).

Sarcomeres is the basic functional unit of skeletal muscle and it has a complex structure, mainly made by two sets of protein filaments: thin filaments (a-actin and associated proteins) and thick filaments (myosin and associated proteins) (Mukund \& Subramaniam, 2020). Macroscopically, the sarcomere is bordered at each end by a dark line (Z-disk) that bisects a lighter I band. At the centre of the sarcomere there is a dense thick filament zone (A-band), with a lighter $\mathrm{H}$-zone. The $\mathrm{M}$-line halves the $\mathrm{H}$-zone. Thin filaments are anchored laterally at the Z-disk while the M-line interconnects the thick filaments (H. E. HUXLEY, 1957). The thick filament is mainly composed of myosin proteins, associated with other non-myosin proteins such as myosin binding proteins (MyBPs) C: this latter contributes to regulate force generation by the actomyosin complex (Ackermann \& Kontrogianni-Konstantopoulos, 2013), and it is associated with titin (Freiburg \& Gautel, 1996) (Gilbert, Cohen, Pardo, Basu, \& Fischman, 1999). The giant elastic protein, titin, extends along the length of the thick filament (Wang, McClure, \& Tu, 1979) (Linke, 2018): it has been found to act as a "molecular template" in the sarcomeres' structure (Horowits, Kempner, Bisher, \& Podolsky, 1986). Similar to thick filaments, also thin filaments are associated with "helping" proteins (Gokhin, Ochala, Domenighetti, \& Fowler, 2015): troponin (TNN-I, TNN-C, TNN-T) and tropomyosin stabilize actin and provide a molecular scaffold for $\mathrm{Ca} 2+$ signalling (Zot \& Potter, 1987). Ca2+ released by fibre depolarization raises the $\mathrm{Ca} 2+$ concentration in cytosol, binding to Ca2+-specific sites of TNN-C, thus forming the initial signal for myofibrillar contraction (Mukund \& Subramaniam, 2020). This allows the actin-myosin interaction (Galińska-Rakoczy et al., 2008). Nebulin for thin filaments has a similar role to titin for thick filaments (Horowits et al., 1986).

Muscle contraction is a complex mechanism realized though the interaction of several proteins. It begins with the activation of sodium channels SCN4A, generating an action potential transmitted to the muscle fibre. This process is called excitation-contraction coupling (ECC) and it occurs at the junction between two membranous structures (T-tubules) and the sarcoplasmic reticulum, called the triad junction (Gash \& Varacallo, 2018) (Mukund \& Subramaniam, 2020). Depolarization of the T tubules causes calcium release from the sarcoplasmic reticulum (SR), and its binding to TNN-C. This led to the shift of tropomyosin, allowing the myosin heads to attach to the actin filaments and creating the so-called cross-bridge (Mukund \& Subramaniam, 2020). This cross-bridge cycle ends with the myosin dissociating from the actin due to ATP hydrolysis (Frontera \& Ochala, 2015). This cycle repeat itself until calcium levels in the myocyte fall, causing the release between actin and myosin.

This difficult network of protein is necessary to maintain a normal muscular function. Several human diseases affecting these muscle proteins, or their metabolism, determine structural and functional abnormalities with relevant consequences on muscular function (Haycock, MacNeil, Jones, Harris, \& Mantle, 1996) (Bruno Corrado, Ciardi, \& lammarrone, 2019).

\section{SLIDING FILAMENT THEORY AND CROSS BRIDGE CYCLE}

The most common theory about muscle contraction was proposed in the 1957 by Andrew Huxley et al. (A. F. HUXLEY, 1957) and has become widely popular and accepted, defining the concept of interaction between actin and myosin (A. F. Huxley \& Niedergerke, 1954) (H. Huxley \& Hanson, 1954). He described the results from the microscopy of single frog muscle fibres. Within each sarcomere, the actin, a globular protein, is organized in thin filaments. These filaments are able to slide over thick filaments composed by myosin, a 
fibrillar protein. The head of the thick filaments attaches to the actin filament creating temporary crossbridges, able to shorten the sarcomere. This process requires energy expenditure, in terms of ATP hydrolysis.

The basic idea of Huxley is that the myosin filament has a subgroup attached to the main filament that can form temporary interactions and attach to sites on the adjacent actin filament (Astumian, 2015); ATP hydrolysis detaches the myosin from actin. When the head is attached to actin, the spring pulls the actin. This cross bridge cycle explains the molecular mechanisms of the sliding filament model.

In spite of strong evidence, the sliding filament theory did not gain any support for several years (Cooke, 2004). In 1966, Gordon et al. (Gordon, Huxley, \& Julian, 1966) added that, at greater lengths, the tension on each actin filament is made up of equal contributions from each bridge overlapping on adjacent myosin.

Even if this theory was able to explain some form of muscle contraction, like isometric and concentric contraction, some mechanisms are not fully described by it.

\section{FORCE ENHANCEMENT THEORY}

In the last 80's, several physiological experiments described some phenomena not explicable according to the sliding filaments theory, like the "force enhancement during stretch" concept (Herzog \& Leonard, 2002a) (Lombardi \& Piazzesi, 1990). Indeed, applying a previous stretch to the sarcomere, exceeding its normal operating length, the force generated by its contraction is higher than the force generated at the same sarcomere length during an isometric contraction without stretch. Huxley et al. in 1980 postulated that a large stretch applied during the plateau of a tetanus leaves the tension raised for a long period. This mechanism is not explicable with the sliding filaments theory, because the number of cross-bridges between action and myosin should be the same at the same sarcomere's length, thus determining the same force. Herzog et al. (Herzog \& Leonard, 2002b) suggest that part of the force enhancement of muscles following stretch is caused by an 'activatable' passive element that changes its stiffness, at a given length, during active stretching.

This residual force enhancement was first observed by Abbott et al. (Abbott \& Aubert, 1952), and predated Huxley's cross-bridge model.

To explain this concept some other theories have been proposed as the "popping sarcomere" theory and the involvement of some passive structure able to increase force following a stretch. The popping sarcomere hypothesis (D. L. Morgan, 1990) (David L Morgan \& Proske, 2004) states that stretch-induced muscular damage comes from non-uniform lengthening of sarcomeres beyond its capacity: the longest sarcomeres will be the weakest. According to Morgan et al. (D. L. Morgan, 1990), the adaptation to eccentric exercise consists of increasing the number of sarcomeres in series, so that a given muscle length corresponds to a shorter sarcomere length.

\section{WINDING FILAMENT THEORY}

Moreover, no mechanisms are able to justify the mechanisms behind the eccentric contraction of the sarcomere, where its contraction generates highest level of tension while it is lengthening. Indeed, lengthening or eccentric contractions have remained unexplained for several years, remaining difficult to understand through just-known theories (K. C. Nishikawa, Lindstedt, \& LaStayo, 2018). 
To explain this concept, several other proteins involved in the sarcomere architecture have been investigated during the last years. Among them, the titin protein, the most represented protein in the skeletal muscle, has been proposed to have a key role in explain force enhancement and mechanism of eccentric muscle contraction, through several hypothesis like the winding filament theory (K. C. Nishikawa et al., 2012). Because titin is bound to thick filaments in the A-band and to thin filaments in the Z-disc (Funatsu et al., 1993), rotation of thin filaments by the cross-bridges must lead to the winding of titin upon them (K. Nishikawa et al., 2011): this begins a process able to store elastic potential energy during isometric force development and active stretch (Linke et al., 2002) (Yamasaki et al., 2001) (Bianco et al., 2007).

The winding filament model provides a simple mechanism by which titin contributes to muscle force development and active shortening (K. C. Nishikawa et al., 2012). It adds an elastic element inside active muscle sarcomeres, trying to complete the sliding filament theory.

\section{PRACTICAL APPLICATION TO SPORT MEDICINE AND REHABILITATION SCIENCE}

Years of scientific research in skeletal muscle physiology tried to make its complex structure and function clearer (Mukund \& Subramaniam, 2020). The importance of these preclinical studies is of widespread interest for their high application to the clinical field: knowing the exact mechanism of muscle contraction must be the base for everyday application of sport science, and it is fundamental in planning training strategies and recovering from muscle injuries. It allows us to understand minute details of molecular cross-talk required for effective coordination between the myriad interacting components for efficient muscle function.

It is the case of eccentric exercise for the treatment of tendinopathy (O'Neill, Watson, \& Barry, 2015) (Loiacono et al., 2019), or the use of isokinetic dynamometer in the prevention of sport injuries (Croisier \& Crielaard, 2001). In the last years, a novel modality of muscle contraction, iso-inertial (Tesch, FernandezGonzalo, \& Lundberg, 2017), is gaining more scientific interest for its potential applications. Muscle contraction is also the anatomical base on which an efficient and individualized training program can be developed (Jiménez-Reyes, Samozino, Brughelli, \& Morin, 2017), also for people with disability (Spera et al., 2019) (Montesano, Tafuri, \& Mazzeo, 2013), and this concept is still not clear for most people (Palermi et al., 2020).

While different molecules have been proposed as method to promote tendon's healing (Sirico et al., 2017) (Bruno Corrado, Mazzuoccolo, et al., 2019), few substances have been studied to promote muscle healing, like PRP (Hamid, Yusof, \& Mohamed Ali, 2014). Knowing physiological mechanism behind muscle contraction could promote new rehabilitative approach and interventional procedures in musculoskeletal disorders, favouring more positive results for patients (Gustafsson, DeFreese, \& Madigan, 2017), trainers, physiotherapists (Bruno Corrado, Ciardi, Fortunato, \& lammarrone, 2019) and doctors (Dewa, Loong, Bonato, Thanh, \& Jacobs, 2014).

\section{REFERENCES}

Abbott, B. C., \& Aubert, X. M. (1952). The force exerted by active striated muscle during and after change of length. The Journal of Physiology, 117(1), 77-86.

Ackermann, M. A., \& Kontrogianni-Konstantopoulos, A. (2013). Myosin binding protein-C slow: A multifaceted family of proteins with a complex expression profile in fast and slow twitch skeletal muscles. Frontiers in Physiology, 4 DEC. https://doi.org/10.3389/fphys.2013.00391 
Astumian, R. (2015). Huxley's Model for Muscle Contraction Revisited: The Importance of Microscopic Reversibility. Topics in Current Chemistry, 369. https://doi.org/10.1007/128_2015_644

Bianco, P., Nagy, A., Kengyel, A., Szatmári, D., Mártonfalvi, Z., Huber, T., \& Kellermayer, M. S. Z. (2007). Interaction forces between F-actin and titin PEVK domain measured with optical tweezers. Biophysical Journal, 93(6), 2102-2109. https://doi.org/10.1529/biophysj.107.106153

Cooke, R. (2004). The sliding filament model: 1972-2004. The Journal of General Physiology, 123(6), 643-656. https://doi.org/10.1085/jgp.200409089

Corrado, B, Albano, M., Caprio, M. G., Di Luise, C., Sansone, M., Servodidio, V., ... Servodio lammarrone, C. (2019). Usefulness of point shear wave elastography to assess the effects of extracorporeal shockwaves on spastic muscles in children with cerebral palsy: An uncontrolled experimental study. Muscles, Ligaments and Tendons Journal, 9(1), 124-130. https://doi.org/10.32098/mlti.01.2019.04

Corrado, Bruno, Ciardi, G., Fortunato, L., \& lammarrone, C. (2019). Burnout syndrome among Italian physiotherapists: a cross-sectional study. European Journal of Physiotherapy, 1-6. https://doi.org/10.1080/21679169.2018.1536765

Corrado, Bruno, Ciardi, G., \& lammarrone, C. S. (2019). Rehabilitation management of pompe disease, from childhood trough adulthood: A systematic review of the literature. Neurology International, 11(2), 7983. https://doi.org/10.4081/ni.2019.7983

Corrado, Bruno, Mazzuoccolo, G., Liguori, L., Chirico, V. A., Costanzo, M., Bonini, I., ... Curci, L. (2019). Treatment of lateral epicondylitis with collagen injections: A pilot study. Muscles, Ligaments and Tendons Journal, 9(4), 584-589. https://doi.org/10.32098/mlti.04.2019.14

Croisier, J. L., \& Crielaard, J. M. (2001). [Isokinetic exercise and sports injuries]. Revue medicale de Liege, 56(5), 360-368.

Davies, G., Riemann, B. L., \& Manske, R. (2015). Current concepts of plyometric exercise. International Journal of Sports Physical Therapy, 10(6), 760-786.

Dewa, C. S., Loong, D., Bonato, S., Thanh, N. X., \& Jacobs, P. (2014). How does burnout affect physician productivity? A systematic literature review. BMC Health Services Research, 14(1), 325. https://doi.org/10.1186/1472-6963-14-325

Exeter, D., \& Connell, D. A. (2010). Skeletal muscle: Functional anatomy and pathophysiology. Seminars in Musculoskeletal Radiology, 14(2), 97-105. https://doi.org/10.1055/s-0030-1253154

Freiburg, A., \& Gautel, M. (1996). A molecular map of the interactions between titin and myosin-binding protein C. Implications for sarcomeric assembly in familial hypertrophic cardiomyopathy. European Journal of Biochemistry, 235(1-2), 317-323. https://doi.org/10.1111/j.1432-1033.1996.00317.x

Frontera, W. R., \& Ochala, J. (2015). Skeletal muscle: a brief review of structure and function. Calcified Tissue International, 96(3), 183-195. https://doi.org/10.1007/s00223-014-9915-y

Funatsu, T., Kono, E., Higuchi, H., Kimura, S., Ishiwata, S., Yoshioka, T., ... Tsukita, S. (1993). Elastic filaments in situ in cardiac muscle: deep-etch replica analysis in combination with selective removal of actin and myosin filaments. The Journal of Cell Biology, 120(3), 711-724. https://doi.org/10.1083/jcb.120.3.711

Galińska-Rakoczy, A., Engel, P., Xu, C., Jung, H. S., Craig, R., Tobacman, L. S., \& Lehman, W. (2008). Structural Basis for the Regulation of Muscle Contraction by Troponin and Tropomyosin. Journal of Molecular Biology, 379(5), 929-935. https://doi.org/10.1016/.j.mb.2008.04.062

Gash, M. C., \& Varacallo, M. (2018). Physiology, Muscle Contraction. StatPearls. StatPearls Publishing.

Gilbert, R., Cohen, J. A., Pardo, S., Basu, A., \& Fischman, D. A. (1999). Identification of the A-band localization domain of myosin binding proteins $\mathrm{C}$ and $\mathrm{H}$ (MyBP-C, MyBP-H) in skeletal muscle. Journal of Cell Science, 112 ( Pt 1, 69-79. 
Gillies, A. R., \& Lieber, R. L. (2011, September). Structure and function of the skeletal muscle extracellular matrix. Muscle and Nerve. NIH Public Access. https://doi.org/10.1002/mus.22094

Gokhin, D. S., Ochala, J., Domenighetti, A. A., \& Fowler, V. M. (2015). Tropomodulin 1 directly controls thin filament length in both wild-type and tropomodulin 4-deficient skeletal muscle. Development (Cambridge, England), 142(24), 4351-4362. https://doi.org/10.1242/dev.129171

Gordon, A. M., Huxley, A. F., \& Julian, F. J. (1966). The variation in isometric tension with sarcomere length in vertebrate muscle fibres. The Journal of Physiology, 184(1), 170-192. https://doi.org/10.1113/jphysiol.1966.sp007909

Grzelkowska-Kowalczyk, K. (2016). The Importance of Extracellular Matrix in Skeletal Muscle Development and Function. In Composition and Function of the Extracellular Matrix in the Human Body. InTech. https://doi.org/10.5772/62230

Gustafsson, H., DeFreese, J. D., \& Madigan, D. J. (2017). Athlete burnout: review and recommendations. Current Opinion in Psychology, 16, 109-113. https://doi.org/10.1016/j.copsyc.2017.05.002

Hamid, M. S. A., Yusof, A., \& Mohamed Ali, M. R. (2014). Platelet-rich plasma (PRP) for acute muscle injury: A systematic review. PLoS ONE, 9(2). https://doi.org/10.1371/journal.pone.0090538

Haycock, J. W., MacNeil, S., Jones, P., Harris, J. B., \& Mantle, D. (1996). Oxidative damage to muscle protein in Duchenne muscular dystrophy. Neuroreport, 8(1), 357-361. https://doi.org/10.1097/00001756-199612200-00070

Herzog, W., \& Leonard, T. R. (2002a). Force enhancement following stretching of skeletal muscle: a new mechanism. The Journal of Experimental Biology, 205(Pt 9), 1275-1283.

Herzog, W., \& Leonard, T. R. (2002b). Force enhancement following stretching of skeletal muscle. Journal of Experimental Biology, 205(9), 1275 LP - 1283.

Horowits, R., Kempner, E. S., Bisher, M. E., \& Podolsky, R. J. (1986). A physiological role for titin and nebulin in skeletal muscle. Nature, 323(6084), 160-164. https://doi.org/10.1038/323160a0

Humphrey, J. D., Dufresne, E. R., \& Schwartz, M. A. (2014, December 11). Mechanotransduction and extracellular matrix homeostasis. Nature Reviews Molecular Cell Biology. Nature Publishing Group. https://doi.org/10.1038/nrm3896

Huxley, A. F. (1957). Muscle structure and theories of contraction. Progress in Biophysics and Biophysical Chemistry, 7, 255-318. https://doi.org/10.1016/S0096-4174(18)30128-8

Huxley, A. F., \& Niedergerke, R. (1954). Structural changes in muscle during contraction: Interference microscopy of living muscle fibres. Nature, 173(4412), 971-973. https://doi.org/10.1038/173971a0

Huxley, H. E. (1957). The double array of filaments in cross-striated muscle. The Journal of Biophysical and Biochemical Cytology, 3(5), 631-648. https://doi.org/10.1083/jcb.3.5.631

Huxley, H., \& Hanson, J. (1954). Changes in the Cross-striations of muscle during contraction and stretch and their structural interpretation. Nature, 173(4412), 973-976. https://doi.org/10.1038/173973a0

Jiménez-Reyes, P., Samozino, P., Brughelli, M., \& Morin, J. B. (2017). Effectiveness of an individualized training based on force-velocity profiling during jumping. Frontiers in Physiology, 7(JAN), 677. https://doi.org/10.3389/fphys.2016.00677

Jones, D. A., \& Rutherford, O. M. (1987). Human muscle strength training: the effects of three different regimens and the nature of the resultant changes. The Journal of Physiology, 391(1), 1-11. https://doi.org/10.1113/jphysiol.1987.sp016721

Lieber, R. L. (2009). Skeletal Muscle Structure, Function, and Plasticity: The Physiological Basis of Rehabilitation: Amazon.it: Lieber, Richard L.: Libri in altre lingue. (Wolters Kluwer Health - Lippincott Williams \& Wilkins, Ed.) (3rd ed.).

Linke, W. A. (2018). Titin Gene and Protein Functions in Passive and Active Muscle. Annual Review of Physiology, 80(1), 389-411. https://doi.org/10.1146/annurev-physiol-021317-121234 
Linke, W. A., Kulke, M., Li, H., Fujita-Becker, S., Neagoe, C., Manstein, D. J., ... Fernandez, J. M. (2002). PEVK domain of titin: An entropic spring with actin-binding properties. In Journal of Structural Biology (Vol. 137, pp. 194-205). Academic Press Inc. https://doi.org/10.1006/jsbi.2002.4468

Loiacono, C., Palermi, S., Massa, B., Belviso, I., Romano, V., Gregorio, A. Di, ... Sacco, A. M. (2019). Tendinopathy: Pathophysiology, Therapeutic Options, and Role of Nutraceutics. A Narrative Literature Review. Medicina (Kaunas, Lithuania), 55(8). https://doi.org/10.3390/medicina55080447

Lombardi, V., \& Piazzesi, G. (1990). The contractile response during steady lengthening of stimulated frog muscle fibres. The Journal of Physiology, 431(1), 141-171. https://doi.org/10.1113/iphysiol.1990.sp018324

Mazzeo, F., Tafuri, D., \& Montesano, P. (2020). Respiratory endurance, pulmonary drugs and sport performance: An analysis in a sample of amateur soccer athletes. Sport Science, 13(1), 11-16.

Montesano, P., Masala, D., Silvestro, M., Cipriani, G., Tafuri, D., \& Mazzeo, F. (2020). Effects of combined training program, controlled diet and drugs on middle-distance amateur runners : A pilot study. Sport Science, 13(1), 17-22.

Montesano, P., Tafuri, D., \& Mazzeo, F. (2013). Improvement of the motor performance difference in athletes of weelchair Basketball. Journal of Physical Education and Sport, 13, 362-370. https://doi.org/10.7752/ipes.2013.03058

Morgan, D. L. (1990). New insights into the behavior of muscle during active lengthening. Biophysical Journal, 57(2), 209-221. https://doi.org/10.1016/S0006-3495(90)82524-8

Morgan, David L, \& Proske, U. (2004). Popping sarcomere hypothesis explains stretch-induced muscle damage. In Clinical and Experimental Pharmacology and Physiology (Vol. 31, pp. 541-545). https://doi.org/10.1111/j.1440-1681.2004.04029.x

Mukund, K., \& Subramaniam, S. (2020, August 13). Skeletal muscle: A review of molecular structure and function, in health and disease. Wiley Interdisciplinary Reviews: Systems Biology and Medicine. Wiley-Blackwell. https://doi.org/10.1002/wsbm.1462

Naugle, K. M., Naugle, K. E., Fillingim, R. B., \& Riley, J. L. (2014). Isometric exercise as a test of pain modulation: Effects of experimental pain test, psychological variables, and sex. Pain Medicine (United States), 15(4), 692-701. https://doi.org/10.1111/pme.12312

Nishikawa, K. C., Lindstedt, S. L., \& LaStayo, P. C. (2018, July 1). Basic science and clinical use of eccentric contractions: History and uncertainties. Journal of Sport and Health Science. Elsevier B.V. https://doi.org/10.1016/i.jshs.2018.06.002

Nishikawa, K. C., Monroy, J. A., Uyeno, T. E., Yeo, S. H., Pai, D. K., \& Lindstedt, S. L. (2012). Is titin a "winding filament"? A new twist on muscle contraction. Proceedings of the Royal Society B: Biological Sciences, 279(1730), 981-990. https://doi.org/10.1098/rspb.2011.1304

Nishikawa, K., Monroy, J., Uyeno, T., Yeo, S., Pai, D., \& Lindstedt, S. (2011). Is titin a "winding filament"? A new twist on muscle contraction. Proceedings. Biological Sciences / The Royal Society, 279, 981 990. https://doi.org/10.1098/rspb.2011.1304

O'Neill, S., Watson, P. J., \& Barry, S. (2015). Why are eccentric exercises effective for achilles tendinopathy? International Journal of Sports Physical Therapy, 10(4), 552-562.

Padulo, J., Laffaye, G., Chamari, K., \& Concu, A. (2013, July). Concentric and Eccentric: Muscle Contraction or Exercise? Sports Health. SAGE Publications. https://doi.org/10.1177/1941738113491386

Palermi, S., Sacco, A. M., Belviso, I., Romano, V., Montesano, P., Corrado, B., \& Sirico, F. (2020). Guidelines for physical activity-a cross-sectional study to assess their application in the general population. Have we achieved our goal? International Journal of Environmental Research and Public Health, 17(11), 1-14. https://doi.org/10.3390/ijerph17113980 
Rice, D. A., McNair, P. J., Lewis, G. N., \& Dalbeth, N. (2014). Quadriceps arthrogenic muscle inhibition: The effects of experimental knee joint effusion on motor cortex excitability. Arthritis Research and Therapy, 16(1). https://doi.org/10.1186/s13075-014-0502-4

Rio, E., Kidgell, D., Purdam, C., Gaida, J., Moseley, G. L., Pearce, A. J., \& Cook, J. (2015). Isometric exercise induces analgesia and reduces inhibition in patellar tendinopathy. British Journal of Sports Medicine, 49(19), 1277-1283. https://doi.org/10.1136/bjsports-2014-094386

Servodio lammarrone, C., Cadossi, M., Sambri, A., Grosso, E., Corrado, B., \& Servodio lammarrone, F. (2016). Is there a role of pulsed electromagnetic fields in management of patellofemoral pain syndrome? Randomized controlled study at one year follow-up. Bioelectromagnetics, 37(2), 81-88. https://doi.org/10.1002/bem.21953

Sirico, F., Ricca, F., DI Meglio, F., Nurzynska, D., Castaldo, C., Spera, R., \& Montagnani, S. (2017). Local corticosteroid versus autologous blood injections in lateral epicondylitis: meta-analysis of randomized controlled trials. European Journal of Physical and Rehabilitation Medicine, 53(3), 483491. https://doi.org/10.23736/S1973-9087.16.04252-0

Sonnery-Cottet, B., Saithna, A., Quelard, B., Daggett, M., Borade, A., Ouanezar, H., ... Blakeney, W. G. (2019). Arthrogenic muscle inhibition after ACL reconstruction: a scoping review of the efficacy of interventions. British Journal of Sports Medicine, 53(5), 289 LP - 298. https://doi.org/10.1136/bjsports-2017-098401

Spera, R., Belviso, I., Sirico, F., Palermi, S., Massa, B., Mazzeo, F., \& Montesano, P. (2019). Jump and balance test in judo athletes with or without visual impairments. Journal of Human Sport and Exercise, 14(Proc4), S937-S947. https://doi.org/10.14198//hse.2019.14.Proc4.56

Sweeney, H. L., \& Hammers, D. W. (2018). Muscle Contraction. Cold Spring Harbor Perspectives in Biology, 10(2). https://doi.org/10.1101/cshperspect.a023200

Tesch, P. A., Fernandez-Gonzalo, R., \& Lundberg, T. R. (2017, April 27). Clinical applications of isoinertial, eccentric-overload (YoYoTM) resistance exercise. Frontiers in Physiology. Frontiers Media S.A. https://doi.org/10.3389/fphys.2017.00241

Vola, E. A., Albano, M., Di Luise, C., Servodidio, V., Sansone, M., Russo, S., ... Vallone, G. (2018). Use of ultrasound shear wave to measure muscle stiffness in children with cerebral palsy. Journal of Ultrasound, 21(3), 241-247. https://doi.org/10.1007/s40477-018-0313-6

Wang, K., McClure, J., \& Tu, A. (1979). Titin: Major myofibrillar components of striated muscle. Proceedings of the National Academy of Sciences of the United States of America, 76(8), 36983702. https://doi.org/10.1073/pnas.76.8.3698

Yamasaki, R., Berri, M., Wu, Y., Trombitás, K., McNabb, M., Kellermayer, M. S., ... Granzier, H. (2001). Titin-actin interaction in mouse myocardium: passive tension modulation and its regulation by calcium/S100A1. Biophysical Journal, 81(4), 2297-2313. https://doi.org/10.1016/S00063495(01)75876-6

Zot, A. S., \& Potter, J. D. (1987). Structural aspects of troponin-tropomyosin regulation of skeletal muscle contraction. Annual Review of Biophysics and Biophysical Chemistry. Annu Rev Biophys Biophys Chem. https://doi.org/10.1146/annurev.bb.16.060187.002535

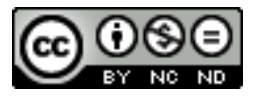

This work is licensed under a Attribution-NonCommercial-NoDerivatives 4.0 International (CC BY-NC-ND 4.0). 